\title{
O SISTEMA VINCULATÓRIO DE PRONUNCIAMENTOS JUDICIAIS DO NOVO CÓDIGO DE PROCESSO CIVIL: DA SUA APLICAÇÃO CONSTITUCIONALMENTE ADEQUADA AO SEU USO ATRAVÉS DO MODELO TOULMIN DE ARGUMENTAÇÃO \\ THE JUDICIAL PRECEDENT SYSTEM OF THE NEW CIVIL PROCEDURE CODE: ITS CONSTITUTIONALLY APPROPRIATE APPLICATION TO USE THROUGH THE TOULMIN MODEL OF ARGUMENTATION
}

\author{
${ }^{1}$ Windsor Malaquias Cordeiro
}

\section{RESUMO}

Os dois pontos nevrálgicos do novo Código de Processo Civil (Novo CPC) são o inédito sistema de precedentes e a nova regulamentação da motivação das decisões judiciais. Registre-se que o Novo CPC não elege uma teoria da argumentação jurídica. Assim, o presente trabalho apresenta criticamente o sistema vinculatório do Novo CPC, fazendo uma análise hermenêutica para a sua aplicação constitucionalmente adequada, bem como avalia se a teoria toulminiana de argumentação é uma proposta teórica capaz de contribuir para a construção de um modelo normativo de fundamentação das decisões judiciais pautadas no art. 927, do referido código.

Palavras-chave: Novo código de processo civil, Precedentes, Hermenêutica constitucional, Modelo toulmin

\section{ABSTRACT}

The two neuralgic points of the new Civil Procedure Code (CPC New) is the unprecedented previous system and the new regulation of motivation of judicial decisions. Register the new CPC does not elect a theory of legal argument. Thus, this study critically presents the linkable system New CPC, through a hermeneutical analysis for their constitutionally proper implementation and assesses whether toulminiana theory of argumentation is a theoretical proposal can contribute to the construction of a normative model of reasoning judicial decisions grounded in art. 927 of that code.

Keywords: New code of civil procedure, Precedent, Constitutional hermeneutics, Toulmin model

\footnotetext{
${ }^{1}$ Mestrando em Direito pela Universidade Federal do Ceará, Ceará (Brasil) E-mail: windsor_adv@yahoo.com.br
} 


\section{INTRODUÇÃO}

O novo Código de Processo Civil (Novo CPC) - Lei n 13.105, de 16 de março de 2015 -, primeiro código de processo civil confeccionado em período democrático ${ }^{1}$, entrou em vigor há poucos dias ${ }^{2}$.

Saliente-se que o código de processo civil é a lei instrumental preeminente do direito civil e subsidiária de diversos ramos do direito, a exemplo do direito eleitoral, do direito do trabalho, do direito administrativo, do direito penal e do direito tributário. ${ }^{3}$

É imperiosa a necessidade do estudo desta novel lei adjetiva, cabendo à academia, inclusive sob o ponto de vista social, deter-se sobre os novos institutos processuais trazidos pela citada regulamentação, com o fim último de traçar balizas teóricas aptas a fomentar a efetividade da função jurisdicional do Estado.

O Novo Código, de fato, está em "verdadeira sintonia fina com a Constituição Federal" e, como se lê na sua exposição de motivos, tem o objetivo expresso de "criar condições para que o juiz possa proferir decisão de forma mais rente à realidade fática subjacente à causa". 4

Essa preocupação é central no século XXI. Com efeito, a partir do novo papel da jurisdição dado pelo neoconstitucionalismo, uma pergunta consideravelmente importante para o direito é: como se decide?

1 No que tange à evolução legal do direito processual civil pátrio, vigorou no Brasil, antes do CPC de 2015, o CPC de 1939, Decreto-Lei ${ }^{\circ} 1.608$, de 18 de setembro de 1939, e o CPC de 1973, Lei n 5.869 , de 11 de janeiro de 1973 , este último apelidado de "Código Buzaid", por ter sido o então Ministro da Justiça Alfredo Buzaid incumbido, em 1961, de elaborar o seu anteprojeto. Tanto o CPC de 1939 quanto o CPC de 1973 foram elaborados em períodos de exceção, a saber, respectivamente, "Estado Novo" (de 1937 a 1945) e "Golpe Militar de 64" (de 1964 a 1988).

2 O CPC de 2015 foi sancionado no dia 16 de março de 2015 pela Presidente da República Dilma Rousseff, publicado no dia 17 de março de 2015, no Diário Oficial da União (DOU), e, a teor do que dispõe o art. 1.045, do Novo Código, vigerá a partir do dia 18 de março de 2016, sexta-feira.

3 Art. 15, do Novo CPC. Na ausência de normas que regulem processos eleitorais, trabalhistas ou administrativos, as disposições deste Código lhes serão aplicadas supletiva e subsidiariamente.

4 Exposição de motivos do Novo CPC: "Com evidente redução da complexidade inerente ao processo de criação de um novo Código de Processo Civil, poder-se-ia dizer que os trabalhos da Comissão se orientaram precipuamente por cinco objetivos: 1) estabelecer expressa e implicitamente verdadeira sintonia fina com a Constituição Federal; 2) criar condições para que o juiz possa proferir decisão de forma mais rente à realidade fática subjacente à causa; 3) simplificar, resolvendo problemas e reduzindo a complexidade de subsistemas, como, por exemplo, o recursal; 4) dar todo o rendimento possível a cada processo em si mesmo considerado; e,

5) finalmente, sendo talvez este último objetivo parcialmente alcançado pela realização daqueles mencionados antes, imprimir maior grau de organicidade ao sistema, dando-lhe, assim, mais coesão." Cf. BRASIL. Código de Processo Civil: anteprojeto/Comissão de Juristas Responsável pela Elaboração de Anteprojeto de Código de Processo Civil. Brasília: Senado Federal, Presidência, 2010. Disponível em: <http://www.senado.gov.br/senado/novocpc/pdf/Anteprojeto.pdf>. Acesso em: 08 set. 2015. 
A par dessa temática, o legislador pátrio, almejando segurança jurídica, positivou no Novo CPC, especificamente no art. 927, um sistema vinculatório de pronunciamentos judiciais.

Cabe aqui, mesmo que de passagem, registrar que há algumas indicações doutrinárias que apontam para uma possível inconstitucionalidade seja da própria normatização de um sistema vinculatório de pronunciamentos judiciais seja de institutos processuais específicos, a exemplo do Incidente de Resolução de Demandas Repetitivas (IRDR), previsto no art. 976, do Novo CPC. Veja-se, respectivamente:

Conforme ensina Neil Duxbury (DUXBURY, Neil. The nature and the authority of precedent. Cambridge: Cambridge Universit Press, 2008), a ideia de observância de julgados anteriores só se molda mais claramente no século XIX, como uma doutrina surgida, desenvolvida pelo próprio Judiciário, sem qualquer obrigação imposta por lei ou outro diploma normativo que expressamente submeta qualquer juiz a julgados próprios ou superiores. Essa é uma firme distinção para a realidade que ora vem se apresentando no Brasil, que está sendo pródigo em produzir prescrições, tanto constitucionais quanto legislativas, para submeter os juízes, sobretudo dos graus iniciais, aos humores dos tribunais superiores. Tal sorte de normatização é impensável na Inglaterra e nos EUA, tanto que autores como Michael Gerhardt (GERHADT, Michael. The power of precendent. New York: Oxford University Press, 2008) chegam a vaticinar que eventual lei nesse sentido seria inconstitucional por violação da separação dos poderes, pois não poderia o Legislativo determinar como o Judiciário iria tomar seus próprios precedente. ${ }^{5}$

(Grifo nosso)

Deixe-se claro, todavia, que entendemos que o IRDR pode ser um eficaz mecanismo de resolução de litígios de massa. Apesar disso, não podemos fechar os olhos e ignorar algumas inconstitucionalidades constantes do texto projetado que violam diversos princípios constitucionais do processo decorrentes da cláusula do devido processo geral. $^{6}$

(Grifo nosso)

Entretanto, à luz da nova hermenêutica constitucional, a normatização de um sistema vinculatório de pronunciamentos judiciais é constitucional, na medida em que proporciona estabilidade, coerência e integridade da e na jurisprudência.

Saliente-se que a coerência, que é o dever de proporcionar a garantia da isonômica aplicação principiológica nos caso semelhantes, assegurará a integridade do direito a partir da força normativa da Constituição. Enquanto que a integridade, no seu aspecto de princípio

\footnotetext{
${ }^{5}$ LOPES FILHO, Juraci Mourão. Precedente e norma: usam-se precedentes judiciais como se aplicam normas legislativas? Revista Opinião Jurídica (Fortaleza), v. 14, 2013, p. 251.

${ }^{6}$ ABBOUD, Georges; CAVALCANTI, Marcos de Araújo. Inconstitucionalidades do incidente de resolução de demandas repetitivas (IRDR) e os riscos ao sistema decisório. Revista de processo. Ano 2015, v. 40, n. 240, mes FEV, páginas 223.
}

Revista de Teorias da Justiça, da Decisão e da Argumentação Jurídica | e-ISSN: 2525-9644| Brasília | v. 2 | n. 1 | p. 247 - 265 | Jan/Jun. 2016. 
jurisdicional, assegurará que o julgador interprete o pronunciamento judicial vinculante de modo a fomentar a coerência moral do ordenamento jurídico.

Não obstante a louvável intenção do legislador em garantir estabilidade, integridade e coerência à jurisprudência, é, em certa medida, preocupante notar que se trata de um sistema inédito tanto no Brasil como no mundo, uma vez que, respectivamente, não se está acostumado a operar com ele na práxis judiciária, bem como não se pode dimensionar as suas eventuais falhas operacionais a partir da experiência de outras nações.

Trata-se, de fato, de um sistema genuinamente brasileiro, uma vez que não se tem notícia de um modelo semelhante, isto é, de um modelo normativo de vinculação de pronunciamentos judiciais, em nenhum país do mundo!

Um caso pontual, mas expoente, dessa tendência normativa brasileira foi o da súmula vinculante, positivada na Constituição, através da Emenda Constitucional $n^{\circ} 45$, no ano de 2004.

Neste peculiar contexto jurídico pátrio, faz-se imprescindível envidar esforços na construção de uma teoria da decisão judicial que aponte os caminhos para que o julgador alcance a resposta correta (é dizer, a resposta constitucionalmente adequada), especialmente no caso em que tem de decidir com base em outras decisões.

Com o advento do Novo CPC, há um agravante potencializado, qual seja, a obrigação legal que juízes e tribunais têm de decidir com base em decisões vinculantes.

Aí residem exatamente os dois pontos nevrálgicos do novo código, a saber: a introdução dos precedentes (art. 926 e ss., do Novo CPC) e as novéis exigências de motivação das decisões judiciais (art. 489 e ss., do Novo CPC).

O novo código de processo civil não elege uma teoria da argumentação jurídica. Nem conseguiria fazê-lo, pois isso é papel da doutrina.

Após pesquisa bibliográfica, não se encontrou nenhuma obra doutrinária que aponte o modelo toulminiano como a teoria da argumentação adequada para a fundamentação das decisões judiciais tomadas com base no art. 927, do Novo CPC.

Uma das contribuições que se propõe com este trabalho é exatamente extirpar ou, pelo menos, minorar essa, ao que tudo indica, carência teórica, utilizando o modelo Toulmin 
de argumentação $^{7}$ na construção de um modelo normativo adequado para a fundamentação de decisão judicial tomada com base em decisões judiciais legalmente vinculantes.

Ressalte-se, ainda, que o estudo da teoria das decisões judiciais é importante, na medida em que contribui para a efetividade da prestação jurisdicional e para a satisfação dos jurisdicionados, com decisões fundamentadas e aptas a produzir efeitos para a sociedade.

\section{COLOCAÇÃO DO PROBLEMA}

No século XX, ocorre uma mudança paradigmática, a saber: a temática da linguagem, até então ignorada, passa a ser dominante na filosofia. Com efeito, aproximadamente a partir do ano de 1960 , tem-se a invasão da filosofia pela linguagem. ${ }^{8}$

Os grandes responsáveis pelas viradas na filosofia são Gottlob Frege, pioneiro na "virada linguística", Ludwig Wittgenstein, expoente da filosofia da linguagem, Martin Heidegger, expoente da filosofia hermenêutica, e Hans-Georg Gadamer, expoente da hermenêutica filosófica. ${ }^{9}$

A denominada "virada linguística" implica, por conseguinte, um novo olhar sobre o fenômeno da interpretação do Direito.

Hans-Georg Gadamer, em sua obra Verdade e Método, mais do que uma virada lingüística, promove uma virada ontológica. É dizer, promove uma virada ontológica da hermenêutica no fio condutor da linguagem: uma reviravolta interpretativa.

É imperioso atentar que, à luz da virada ontológico-linguística de Gadamer, o ato de interpretação é um aplicar. Em síntese, é um ato de "dar/atribuir sentido".

O Direito não ficou imune a essa mudança paradigmática. Herbert Lionel Adolphus Hart, filósofo do direito, positivista, é reconhecido como o introdutor da virada linguística na teoria do direito. Cita-se, em seguida, Friedrich Müller, jurista alemão, destacado teórico de corrente denominada de pós-positivista, que nada mais é do que o modelo de Direito pautado

\footnotetext{
7 Cf. TOULMIN, Stephen. Os usos do argumento. Traduzido por Reginaldo Guarany. 2. ed. São Paulo: Martins Fontes, 2006.

8 STRECK, Lenio Luiz. O efeito vinculante das súmulas e o mito da efetividade: uma crítica hermenêutica. In: BONAVIDES, Paulo; LIMA, Francisco Gérson Marques de; BEDÊ, Fayga Silveira. (Coord.). Constituição e Democracia Estudos em homenagem ao Professor J. J. Gomes Canotilho. São Paulo: Malheiros, 2006, p.

396. ${ }^{9}$ Cf. OLIVEIRA, Manfredo Araújo de. A Reviravolta Linguístico-Pragmática na Filosofia Contemporânea. São

Paulo: $\quad$ Loyola, 2006.
} 
no linguistic turn que busca a superação das perspectivas do positivismo, sem desconsiderar os seus ganhos teóricos. Daí ser "pós" e não antipositivismo. ${ }^{10}$

Estabeleceu-se, enfim, um novo conceito de norma jurídica, que não se confunde mais com texto normativo.

É possível afirmar - pautado em Lenio Luiz Streck, especialmente na sua obra Hermenêutica Jurídica e(m) Crise - que, em tempos denominados pós-positivistas, há uma pergunta inquietante, a saber: como se interpreta?

De fato, a temática preeminente no século XX foi a interpretação do direito.

Ocorre que a preocupação mudou! Não que o supracitado tema tenha sido esgotado pela doutrina e que a resposta para a referida pergunta já esteja pronta e acabada. Pelo contrário, o caminho ainda é obscuro.

No entanto, é fundamental perceber que, no século XXI, precisamente nesta última década, com o novo papel da jurisdição dado pelo neoconstitucionalismo, uma pergunta central para a ciência jurídica passou a ser: como se decide?

Essa problemática se ramificou na seguinte indagação: como se decide com base em outras decisões? E, com o advento do Novo CPC, uma pergunta fundamental para o processo civil brasileiro contemporâneo é: como se decide com base em pronunciamentos judiciais legalmente vinculantes?

Na tentativa de delinear parâmetros para a construção da resposta no caso concreto, nos quais se assegure ao jurisdicionado segurança jurídica, o legislador pátrio inovou o ordenamento jurídico, estabelecendo, à brasileira, um sistema vinculatório de pronunciamentos judiciais no art. 927, do Novo CPC.

A seu turno, o Fórum Permanente de Processualistas Civis (FPPC), mais preocupado em ressaltar a força normativa dos precedentes do que a sua força hermenêutica, formulou o seguinte enunciado:

Enunciado $n^{\circ} 170$ do FPPC:

As decisões e precedentes previstos nos incisos do caput do art. 927 são vinculantes aos órgãos jurisdicionais a eles submetidos. ${ }^{11}$

${ }^{10}$ MÜLLER, Friedrich. O novo paradigma do direito: introdução à teoria e metódica estruturantes. 3. ed. rev. atual.e ampl. São Paulo: Editora Revista dos Tribunais, 2013, p. 10.

${ }^{11}$ DIDIER JR., Fredie. Novo Código de Processo Civil: comparativo com o código de 1973. Salvador: Ed. Salvador: Juspodivm, 2015, p. 432.

Revista de Teorias da Justiça, da Decisão e da Argumentação Jurídica | e-ISSN: 2525-9644| Brasília | v. 2 | n. 1 | p. 247 - 265 | Jan/Jun. 2016. 
(Grifo nosso)

Frise-se que o dever de fundamentação das decisões judiciais é uma garantia geral, isto é, constitucional e legal. Na veste de garantia constitucional, esse dever encontra-se disposto no art. 93, inciso IX, da Constituição Federal. A outro giro, na veste de garantia legal, o dever de motivação das decisões judiciais, no que tange ao processo civil, está insculpido no art. 11, do Novo CPC.

O legislador pátrio, ao disciplinar a matéria, no art. 489, $\S 1^{\circ}$, do Novo $\mathrm{CPC}$, apresentou, de forma louvável, uma solução para o dever constitucional de fundamentar as decisões judiciais. Como seria difícil apontar quais as exigências para que a decisão se considere motivada, enumerou, por ser mais passível de previsão, as situações em que ela não será tida como tal.

Temos aqui um enorme desafio, qual seja: entender o que realmente vincula em uma decisão legalmente vinculante. Premissa essa fundamental para bem aplicar os pronunciamentos judiciais vinculantes do art. 927, do Novo CPC, utilizando-os na motivação das decisões judiciais futuras, sob pena de malferir o art. $489, \S 1^{\circ}$, especialmente nos incisos V e VI, do Novo CPC.

Expõe-se, en passant, o problema: será vinculante o dispositivo do julgado ou a sua fundamentação? Na teoria dos precedentes judiciais, o que é ratio decidendi e obiter dictum? Ademais, o que é distinguishing e overruling?

O Brasil é um país fortemente influenciado pelo sistema jurídico romano-germânico (civil law), enquanto que a teoria dos precedentes judiciais, normatizada à brasileira pelo Novo CPC, tem origem no sistema jurídico anglo-americano (common law).

Com essa mudança paradigmática no sistema decisório, os aspectos processuais da fundamentação das decisões judiciais ganharam extremo destaque. Neste ínterim, faz-se imperioso refletir se o modelo que estrutura as partes da decisão utilizado no CPC de 1973 e mantido no CPC de 2015, precisamente no art. 489, incisos I, II e III, é o mais adequado a essa nova sistemática.

Ademais, é crucial perceber que a exigência constitucional do dever de motivação das decisões judiciais não basta em si mesma, uma vez que não garante a resposta 
constitucionalmente adequada, ou em termos dworkinianos, correta ${ }^{12}$, nem garante a individualização da decisão judicial.

Leonard Schmitz, compartilhando dessa opinião, leciona que "dizer que existe uma obrigação à fundamentação é ainda dizer muito pouco sobre a fundamentação em si." 13

No mesmo passo, Lenio Streck assinala que: “A exigência de fundamentação não se resolve com "capas argumentativas" ${ }^{\prime 14}$. E, ainda na mesma linha de entendimento, Juraci Mourão Lopes Filho, em palestra no dia 28 de agosto de 2015, no auditório da Justiça Federal do Ceará, em evento denominado "III Ciclo de Palestras sobre o Novo Código de Processo Civil", asseverou que a "decisão judicial não pode ser um registro de um diálogo entre surdos".

Com efeito, fere o princípio constitucional do contraditório o fato de a parte autora expor os seus argumentos, a parte ré expor os seus contra-argumentos e o juiz, por sua vez, decidir sem considerá-los.

Certo de que o ato de interpretar e o ato de decidir possuem uma simbiose teórica, afinal de contas compreende-se para decidir, o presente trabalho enfrenta esta temática, com foco no sistema vinculatório do Novo CPC.

\section{O SISTEMA VINCULATÓRIO DO NOVO CPC: da sua aplicação} constitucionalmente adequada

$A b$ initio, registre-se que, quanto ao embasamento filosófico, o presente trabalho se pauta na hermenêutica filosófica de Hans-Georg Gadamer ${ }^{15}$.

Quanto à concepção de Direito, adota-se a teoria de Ronald Dworkin ${ }^{16}$, pensador pós-positivista (ou, como prefere alguns, não positivista), adepto de um conceito semântico de

${ }^{12}$ STRECK, Lenio Luiz. Hermenêutica jurídica e(m) crise: uma exploração hermenêutica da construção do Direito. 11. ed. rev., atual. e ampl. Porto Alegre: Livraria do Advogado, 2014, p. 426.

${ }^{13}$ SCHMITZ, Leonard Ziesemer. Fundamentação das decisões judiciais: a crise na construção de respostas no processo civil. São Paulo: Editora Revista dos Tribunais, 2015, p. 34.

${ }^{14}$ STRECK, Lenio Luiz. Hermenêutica jurídica e(m) crise: uma exploração hermenêutica da construção do Direito. 11. ed. rev., atual. e ampl. Porto Alegre: Livraria do Advogado, 2014, p. 433.

${ }^{15}$ Cf. GADAMER, Hans-Georg. Verdade e Método I: traços fundamentais de uma hermenêutica filosófica. 9. ed. Tradução de Flávio Paulo Meurer. Rio de Janeiro: Vozes, 2008.

${ }^{16}$ Cf. DWORKIN, Ronald. Levando os direitos a sério. 3. ed. Tradução de Nelson Boeira. São Paulo: Editora WMF Martins Fontes, 2010. 
norma. É apontado como interpretativista, máxime por ser autor de uma valiosa teoria interpretativa constitucional, que defende que as normas com estrutura de princípios recebem os valores da sociedade, aproximando o Direito da Moral.

Neste passo, o presente artigo se desenvolve com a ideia de que Direito é interpretação, é um atribuir sentido aos textos normativos; ou, como leciona Lenio Luiz Streck $^{17}$, direito é uma questão de caso concreto.

É oportuno ainda frisar, nestas notas de esclarecimento quanto ao aporte teórico, que parte da doutrina brasileira equivoca-se quanto ao conceito de "precedente", confundindo-o com súmula e jurisprudência. ${ }^{18}$

Juraci Mourão Lopes Filho, na sua obra Os precedentes judiciais no constitucionalismo brasileiro contemporâneo, apresenta uma nova teoria do uso e aplicação dos precedentes judiciais no Brasil, adequada às atuais exigências filosóficas, teóricas e práticas do constitucionalismo contemporâneo.

O citado autor propõe o uso e aplicação mediante a força hermenêutica da cada julgado, aferida por elementos não apenas formais, mas também materiais de coerência e justificação, evitando, assim, a redução do precedente à norma.

Tomando por base o conceito de "precedente" proposto por Juraci Mourão (decisão judicial que proporciona ganho de sentido para o sistema jurídico $)^{19}$, estabelece-se, para fins de trabalho, que "pronunciamentos judiciais" é expressão gênero, da qual são espécies a súmula, a decisão, o acórdão, a jurisprudência, as orientações do plenário ou do órgão especial de tribunal e o próprio precedente.

Aproveita-se o ensejo para asseverar que se tem discernimento de que nenhuma teoria está livre de falhas. Neste diapasão, é certo que a concepção interpretativista que compõe o nível basilar da teorização do Direito adotada para a compreensão do tema proposto também tem seus pontos frágeis.

${ }^{17}$ Cf. STRECK, Lenio Luiz. Hermenêutica jurídica e(m) crise: uma exploração hermenêutica da construção do Direito. 11. ed. rev., atual. e ampl. Porto Alegre: Livraria do Advogado, 2014.

${ }^{18}$ LOPES FILHO, Juraci Mourão. Os precedentes judiciais no constitucionalismo brasileiro contemporâneo. Salvador: Juspodivm, 2014, p. 125.

${ }^{19}$ LOPES FILHO, Juraci Mourão. Os precedentes judiciais no constitucionalismo brasileiro contemporâneo. Salvador: Juspodivm, 2014, p. 281-282. 
Transcreve-se a oportuna a reflexão que Juliana Cristine Diniz Campos e Felipe Braga Albuquerque fazem sobre a virada lingüística no interpretar da Constituição:

O reconhecimento de que a interpretação é uma dimensão constitutiva do Direito não implica transformar o ato de interpretação em um ato de vontade discricionário, nem implica uma filiação a qualquer relativismo ético. Em seu papel de ciência histórica, o Direito precisa ser enfrentado sob uma perspectiva hermenêutica, mas condicionado pela objetividade e pela materialidade da norma positivada. ${ }^{20}$

(Grifo nosso)

De fato, deve-se combater o problema da discricionariedade (subjetivista-axiologista) do juiz. E nesse sentido é salutar o advento do sistema vinculatório de pronunciamentos judiciais do Novo CPC.

Ocorre que não é impedido o juiz de interpretar que se atingirá a segurança jurídica, enquanto (mera) previsibilidade na resposta judicial. Trata-se, nas palavras de Georges Abboud, de uma "ficção - ou até mesmo ingenuidade -“212, pois, uma vez sendo impossível não atribuir sentidos aos textos, à luz das lições da hermenêutica gadameriana, só iríamos substituir o juiz boca da lei pelo juiz boca da súmula ou de qualquer outro pronunciamento vinculante.

A segurança jurídica que se deve almejar é a que proporciona coerência sistêmica. Neste ponto, o presente trabalho apóia-se na filosofia do Direito de Ronald Dworkin, a qual propõe uma teoria de unificação da moral individual, da justificação legal e da legitimação política (Direito como integridade) ${ }^{22}$.

Por sua vez, o controle do solipsismo na atribuição de sentido fortalece-se ao se exigir que o juiz, quando da confecção da decisão, fundamente a sua fundamentação ${ }^{23}$.

Para Dworkin, o Judiciário é o fórum do princípio. Deve, portanto, o juiz decidir por princípios, e não por política, economia, religião ou outros argumentos axiológicos. As

${ }^{20}$ CAMPOS, Juliana Cristine Diniz; ALBUQUERQUE, Felipe Braga. Nova hermenêutica constitucional e (in)segurança jurídica: características e crítica da virada linguística no interpretar da constituição. Revista Questio Iuris, v. 8, 2015, p. 790.

${ }^{21}$ ABBOUD, Georges. Do genuíno precedente do stare decisis ao precedente brasileiro: os fatores histórico, hermenêutico e democrático que os diferenciam. In: DIDIER JR., Fredie. [et al.] (coordenadores). Precedentes. Salvador: Juspodivm, 2015, Cap. 18, p. 402.

${ }^{22}$ Cf. DWORKIN, Ronald. O Império do Direito. 3. ed. Tradutor: Jefferson Luiz Camargo. São Paulo: Editora WMF Martins Fontes, 2014.

${ }^{23}$ STRECK, Lenio Luiz. Hermenêutica jurídica e(m) crise: uma exploração hermenêutica da construção do Direito. 11. ed. rev., atual. e ampl. Porto Alegre: Livraria do Advogado, 2014, p. 432. 
decisões judiciais fundamentadas em argumentos de princípio são compatíveis com os princípios democráticos, sendo certo que o juiz não constrói leis, mas segue padrões interpretativos. $^{24}$

Assim, é natural que o julgador interprete, atribuindo sentidos aos enunciados normativos. E, quando o enunciado normativo é um pronunciamento judicial vinculante, como nos casos do art. 927, do Novo CPC, mais ainda se justifica a tarefa hermenêutica, máxime pelo fato de que os pronunciamentos judiciais vinculantes têm estrutura normativa de princípio e, portanto, são aplicados na dimensão de peso ou de importância, e não no tudo ou nada, típico de uma norma-regra legislativa. ${ }^{25}$

Equivocada será a doutrina que defender a pureza de sentidos na aplicação dos pronunciamentos judiciais legalmente vinculantes dispostos nos cinco incisos do referido dispositivo legal.

Não permitir que o julgador interprete os precedentes ou qualquer decisão ou súmula vinculante aprisionará os sentidos destes enunciados. Que, note-se, são textos. E, como textos, é natural que sejam interpretados.

Deve-se atentar que a função principal dos precedentes é o enriquecimento hermenêutico do sistema jurídico. ${ }^{26}$

A proibição de interpretar os pronunciamentos judiciais legalmente vinculantes promoverá um indesejado retrocesso teórico para a aplicação puramente semântica dos enunciados jurídicos, desconectada do caso concreto.

Saliente-se que Friedrich Müller, jusfilósofo alemão, um dos mais importantes teóricos na contemporaneidade na tradição continental, ao desenvolver um conceito concreto de norma, de cariz pós-positivista, demonstra, na sua obra Teoria Estruturante do Direito (TED), que a norma nunca é ante casum, isto é, não há norma em abstrato de forma meramente semântica. ${ }^{27}$

${ }^{24}$ DWORKIN, Ronald. Levando os direitos a sério. 3. ed. Tradução de Nelson Boeira. São Paulo: Editora WMF Martins Fontes, 2010, p. 129.

${ }^{25}$ DWORKIN, Ronald. Levando os direitos a sério. 3. ed. Tradução de Nelson Boeira. São Paulo: Editora WMF Martins Fontes, 2010, p. 42.

${ }^{26}$ LOPES FILHO, Juraci Mourão. Os precedentes judiciais no constitucionalismo brasileiro contemporâneo. Salvador: Juspodivm, 2014, p. 307.

${ }^{27}$ Cf. MÜLLER, Friedrich. Teoria Estruturante do Direito I. 3. ed. rev. e atual. São Paulo: Editora Revista dos Tribunais, 2011.

Revista de Teorias da Justiça, da Decisão e da Argumentação Jurídica | e-ISSN: 2525-9644| Brasília | v. 2 | n. 1 | p. 247 - 265 | Jan/Jun. 2016. 
Nesse ínterim, tem-se que os pronunciamentos judiciais vinculantes elencados no artigo 927, do Novo CPC, quando da sua aplicação e do seu uso pelos juízes e tribunais, não dispensam, respectivamente, a atividade interpretativa nem a atuação em contraditório. Isto é, devem os julgadores atribuir sentidos aos pronunciamentos judiciais vinculantes e fomentar que as partes envolvidas no litígio contribuam na escolha da norma mais adequada ao caso concreto.

Com efeito, no processo judicante-decisional, a aplicação de um genuíno precedente ou de qualquer pronunciamento judicial vinculante é um ato hermenêutico, leia-se: um ato de atribuição de sentido, e não um mero ato mecânico ou subsuntivo.

Ademais, pautado em uma lógica argumentada, deve o julgador assegurar a manifestação das partes litigantes acerca da forma correta para a aplicação (ou acerca da eventual não aplicação) de um pronunciamento judicial vinculante no caso concreto.

Desse modo, em sendo a aplicação dos pronunciamentos judiciais postos no art. 927, do Novo CPC, um ato hermenêutico, em que aspecto eles são vinculantes? Ora, o caráter vinculante dos pronunciamentos judiciais está na garantia da isonômica aplicação principiológica no julgamento de casos semelhantes, assegurando estabilidade, integridade e coerência da e na jurisprudência.

A outro giro, sugere-se, neste trabalho, que da garantia fundamental à motivação da decisão judicial, insculpida no art. 93, inciso IX, da Constituição Federal, e reproduzida, por simetria, no art. 11, do Novo CPC, surge, para o cidadão, em respeito à singularidade dos casos, o direito fundamental à individualização da decisão judicial e, para o Estado-Juiz, o dever de fundamentar a sua fundamentação, impedindo, assim, a estandardização/padronização na construção da resposta no caso concreto, especialmente naqueles que envolvem questões fáticas e jurídicas.

De fato, como leciona Paulo Bonavides, no conceito de garantia está a "moldura protetora do direito". Citando Rafel Bielsa, expõe o que isso quer dizer:

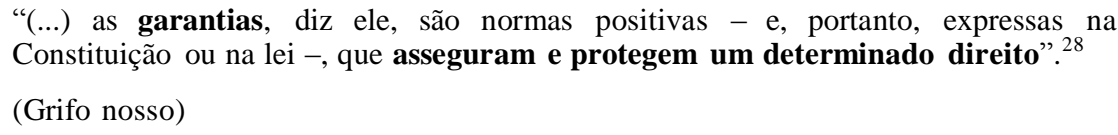

${ }^{28}$ BONAVIDES, Paulo. Curso de direito constitucional. 30. ed. atual. São Paulo: Malheiros, 2015, p. 539. 
A ideia de "resposta correta" foi introduzida e desenvolvida na doutrina pátria por Lenio Streck. Por pertinente, cita-se trecho esclarecedor:

\begin{abstract}
Não se pode fazer uma leitura raza do art. 93, IX, da CF. [...] Ou seja, o juiz não deve "explicar" aquilo que o "convenceu"...Deve, sim, explicitar os motivos de sua compreensão, oferecendo uma justificação (fundamentação) de sua interpretação, na perspectiva de demonstrar como a interpretação oferecida por ele é a melhor para aquele caso (mais adequada à Constituição ou, em termos dworkinianos, correta), num contexto de unidade, integridade e coerência com relação ao Direito da Comunidade Política. ${ }^{29}$
\end{abstract}

(Grifo nosso)

Deve, portanto, o julgador, na confecção da decisão judicial, enfrentar todos os argumentos e contra-argumentos expostos pelas partes no processo, explicitando exaustivamente os motivos de sua compreensão (isto é, fundamentando a sua "fundamentação"), com o fito de identificar, a seu turno, os fundamentos determinantes do próprio pronunciamento judicial vinculante em foco, bem como de demonstrar que o caso sob julgamento se ajusta exatamente àqueles fundamentos.

Fundamentar uma decisão judicial não se resume a fazer um acoplamento mecânico da lei (premissa maior) à situação de fato (premissa menor). Em verdade, não se concebe mais a imaginária separação entre questões de fato e questões de direito, acreditando, como bem ironiza Leonard Schmitz, que "exista julgamento de teses jurídicas sem fatos"30.

Daí porque se sugere que, no modelo estrutural dos elementos essenciais da decisão judicial, deve constar Relatório, Fundamentação da interpretação, Interpretação e Dispositivo. Com efeito, o ultrapassado modelo do CPC de 1973, de cariz juspositivista, e, equivocadamente, mantido no CPC de 2015, o qual determina constar apenas Relatório, Fundamentos e Dispositivo, deve ser imediatamente abolido.

Neste passo, explica-se as 04 (quatro) estruturas do modelo proposto: a) Relatório: onde o julgador irá registrar todos os argumentos e contra-argumentos expostos pelas partes no processo; b) Fundamentação da interpretação: onde o julgador irá explicitar exaustivamente os motivos de sua compreensão, identificando os fundamentos determinantes do pronunciamento judicial vinculante em foco, bem como demonstrando que o caso sob julgamento se ajusta exatamente àqueles fundamentos; c) Interpretação: onde o julgador, a

STRECK, Lenio Luiz. Hermenêutica jurídica e(m) crise: uma exploração hermenêutica da construção do Direito. 11. ed. rev., atual. e ampl. Porto Alegre: Livraria do Advogado, 2014, p. 432-433.

30 SCHMITZ, Leonard Ziesemer. Fundamentação das decisões judiciais: a crise na construção de respostas no processo civil. São Paulo: Editora Revista dos Tribunais, 2015, p. 78.

Revista de Teorias da Justiça, da Decisão e da Argumentação Jurídica | e-ISSN: 2525-9644| Brasília | v. 2 | n. 1 | p. 247 - 265 | Jan/Jun. 2016. 
partir das singularidades do caso concreto, irá expor o sentido atribuído ao pronunciamento judicial legalmente vinculante ou a qualquer outro enunciado normativo/disposição/texto normativo apreciado no julgado. Isto é, onde o julgador irá expor a norma; e d) Dispositivo: onde o juiz irá apresentar a resposta correta (constitucionalmente adequada), resolvendo as questões que as partes lhe submeteram.

\section{O SISTEMA VINCULATÓRIO DO NOVO CPC: do seu uso através do modelo}

\section{Toulmin de argumentação}

O estudo da argumentação jurídica se faz cada vez mais imprescindível, visto que tem sido progressivamente exigido, na legislação processual civil, a atuação em contraditório do julgador pátrio, a exemplo do art. 10 e do art. 489, $\S 3^{\circ}$, ambos do Novo CPC.

A ultrapassada dogmática jurídica positivista-normativista, que busca a prénormatização do sentido do texto, suprimindo a ação do tempo e da história, e que, infelizmente, ainda tem guarida entre boa parte dos juristas brasileiros em pleno século XXI, caso não rechaçada, colocará em cheque o judicatismo decisório pátrio, uma vez que esta doutrina vai de encontro ao novo papel da jurisdição dado pelo neoconstitucionalismo.

Direito, como dito, é interpretação, e não matemática. Portanto, propõe-se o abandono dos métodos pela hermenêutica, pela argumentação racional.

Visando uma aplicação constitucionalmente adequada do sistema vinculatório de pronunciamentos judiciais do novo código de processo civil brasileiro, sugere-se a substituição da lógica formal do silogismo juspositivista, a qual reflete um modelo matemático de raciocínio ${ }^{31}$, pelo modelo substancial de argumentação de Stephen Toulmin.

Stephen Toulmin propõe o seguinte layout de argumentos $^{32}$ :

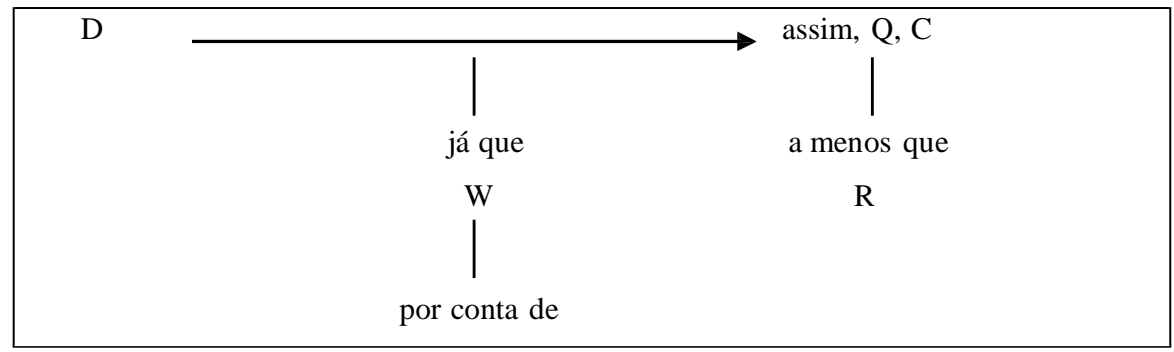

${ }^{31}$ TOULMIN, Stephen. Os usos do argumento. Traduzido por Reginaldo Guarany. 2. ed. São Paulo: Martins Fontes, 2006, p. 154.

32 TOULMIN, Stephen. Os usos do argumento. Traduzido por Reginaldo Guarany. 2. ed. São Paulo: Martins 


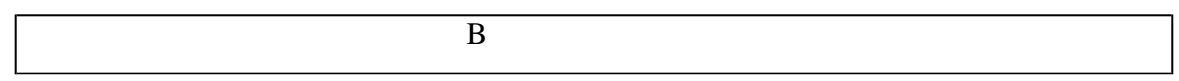

Ressalte-se que essa teoria foi desenvolvida em obra publicada originalmente em inglês com o título The Uses of Argument no ano de 1958. Esclarece-se, por ser imprescindível ao entendimento da teoria, que: i) a letra " $\mathrm{D}$ " atine à palavra inglesa Data, que significa "dado/dados/informação"; ii) a letra "W" atine à palavra inglesa Warranty, que significa "garantia"; iii) a letra "B" atine à palavra inglesa Base, que significa "base/apoio"; iv) a letra "Q" atine à palavra inglesa Qualification, que significa "qualificações/condições", sendo certo que, para a melhor compreensão da ideia do autor, utilizar-se-á como o correspondente significado a palavra "presumivelmente"; v) a letra "C" atine à palavra inglesa Conclusion, que significa "conclusão; e, por fim, vi) a letra "R" atine à expressão inglesa to get Rid of, que significa "refutar/descartar".

O referido autor, a fim de melhor explicitar a sua teoria, desenvolve o uso do argumento em um caso concreto, assim exemplificando ${ }^{33}$ :

\begin{tabular}{|c|c|c|}
\hline \multirow{10}{*}{$\begin{array}{l}\text { Harry nasceu } \\
\text { nas Bermudas }\end{array}$} & & assim, presumivelmente, \\
\hline & $\mid$ & Harry nas Bermudas é um \\
\hline & já que & súdito britânico \\
\hline & Um homem nascido & 1 \\
\hline & nas Bermudas será, & a menos que \\
\hline & em geral, súdito britânico & Seus pais sejam estrangeiros \\
\hline & 1 & ou ele se tenha tornado \\
\hline & por conta de & americano naturalizado \\
\hline & Os seguintes estatutos e & \\
\hline & outros dispositivos legais: & \\
\hline
\end{tabular}

A seu turno, Juraci Mourão aplica o supracitado modelo para a fundamentação em precedentes da seguinte maneira ${ }^{34}$ :

\begin{tabular}{|c|c|}
\hline Precedente $(\mathrm{D}) \longrightarrow$ & $\begin{array}{c}\text { Resposta próxima ou remota (Q), } \\
\text { salvo se (R), para nova decisão (C) }\end{array}$ \\
(Aferição da força hermenêutica \\
do precedente)
\end{tabular}

33 TOULMIN, Stephen. Os usos do argumento. Traduzido por Reginaldo Guarany. 2. ed. São Paulo: Martins Fontes, 2006, p. 151.

${ }^{34}$ LOPES FILHO, Juraci Mourão. Os precedentes judiciais no constitucionalismo brasileiro contemporâneo. 
A partir dessas lições teóricas, propõe-se que a argumentação disposta na fundamentação de decisão judicial tomada com base no art. 927, do Novo CPC, seja desenvolvida da seguinte forma:

\begin{tabular}{|c|c|}
\hline 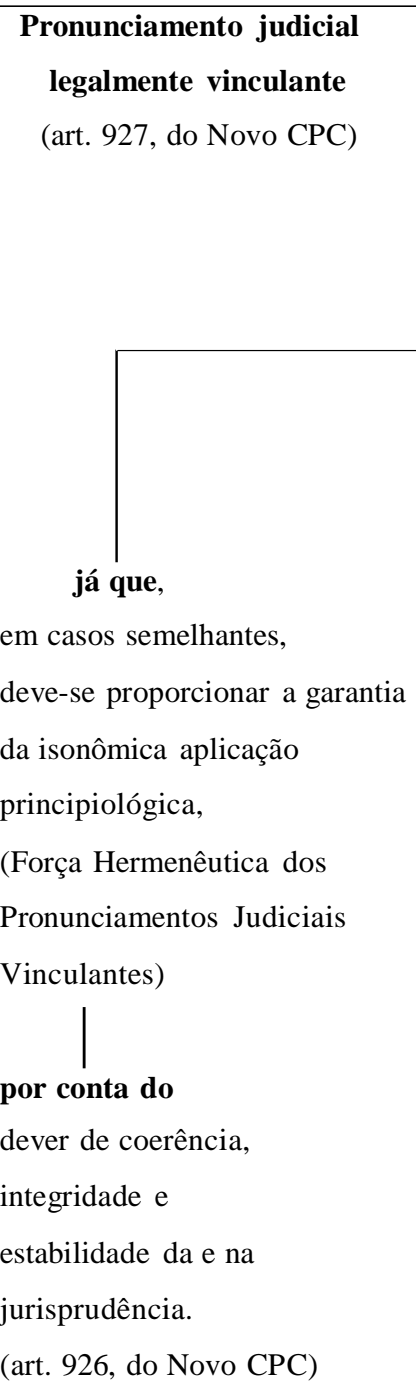 & $\begin{array}{c}\text { assim, com maior ou menor grau de } \\
\text { força hermenêutica } \\
\text { (identificar seus fundamentos determinantes) } \\
- \text { art. } 489, \S 1^{\circ} \text {, inciso } \mathrm{V} \text {, do Novo CPC -, } \\
\text { o pronunciamento judicial legalmente vinculante será } \\
\text { utilizado (ou não) para fundamentar a } \\
\text { decisão judicial (interlocutória/sentença/acórdão). } \\
\text { a menos que } \\
\text { reste demonstrada a distinção no caso em julgamento } \\
\text { (distinguishing) } \\
\text { ou a superação do entendimento } \\
\text { (overruling) } \\
\text { - art. } 489, \S 1^{\circ} \text {, inciso VI, do Novo CPC -. }\end{array}$ \\
\hline
\end{tabular}

É dizer, na apreciação de um caso concreto, tomando-se um pronunciamento judicial vinculante elencado no art. 927, do Novo CPC, já que, em casos semelhantes, deve-se proporcionar a garantia da isonômica aplicação principiológica (que nada mais é do que a própria força hermenêutica do pronunciamento judicial vinculante), por conta do dever de coerência, integridade e estabilidade da e na jurisprudência insculpido no art. 926, do Novo CPC, assim, identificado os seus fundamentos determinantes, os quais o fazem vincular em 
uma dimensão de peso ou de importância, isto é, com um grau maior ou menor de força, e, portanto, atendendo ao requisito do art. 489, $\S 1^{\circ}$, inciso $\mathrm{V}$, do Novo CPC, será o pronunciamento vinculante em foco utilizado (ou não) para fundamentar a decisão judicial respectiva, seja ela uma decisão interlocutória, uma sentença ou um acórdão, a menos que reste demonstrada a existência de distinção no caso em julgamento (distinguishing) ou a superação do entendimento (overruling), conforme dispõe o art. 489, $\S 1^{\circ}$, inciso VI, do Novo CPC.

\section{CONCLUSÕES}

Em suma, tem-se que os pronunciamentos judiciais vinculantes elencados no artigo 927, do Novo CPC, quando da sua aplicação e do seu uso pelos juízes e tribunais, não dispensam, respectivamente, a atividade interpretativa nem a atuação em contraditório.

Por fim, a teoria toulminiana de argumentação é uma proposta teórica capaz de contribuir para a construção de um modelo normativo de fundamentação das decisões judiciais tomadas com base no art. 927, do Novo CPC, uma vez que estabelece minimamente um conjunto de critérios com base nos quais se deve aferir o cumprimento ou não de determinado pronunciamento judicial legalmente vinculante. 


\section{REFERÊNCIAS BIBLIOGRÁFICAS}

ABBOUD, Georges. Jurisdição constitucional e direitos fundamentais. São Paulo: Revista dos Tribunais, 2011.

; CAVALCANTI, Marcos de Araújo. Inconstitucionalidades do incidente de resolução de demandas repetitivas (IRDR) e os riscos ao sistema decisório. Revista de processo. Ano 2015, v. 40, n. 240, mes FEV, páginas 221-242.

- Do genuíno precedente do stare decisis ao precedente brasileiro: os fatores histórico, hermenêutico e democrático que os diferenciam. In: DIDIER JR., Fredie. [et al.] (coordenadores). Precedentes. Salvador: Juspodivm, 2015, Cap. 18, p. 399-404.

BONAVIDES, Paulo. Curso de direito constitucional. 30. ed. atual. São Paulo: Malheiros, 2015.

BRASIL. Código de Processo Civil: anteprojeto/Comissão de Juristas Responsável pela Elaboração de Anteprojeto de Código de Processo Civil. Brasília: Senado Federal, Presidência, 2010.2 Disponível em: <http://www.senado.gov.br/senado/novocpc/pdf/Anteprojeto.pdf>. Acesso em: 08 set. 2015.

CAMPOS, Juliana Cristine Diniz; ALBUQUERQUE, Felipe Braga. Nova hermenêutica constitucional e (in)segurança jurídica: características e crítica da virada linguística no interpretar da constituição. Revista Questio Iuris, v. 8, p. 774-792, 2015.

DIDIER JR., Fredie. Novo Código de Processo Civil: comparativo com o código de 1973. Salvador: Ed. Salvador: Juspodivm, 2015, p. 432.

DWORKIN, Ronald. Levando os direitos a sério. 3. ed. Tradução de Nelson Boeira. São Paulo: Editora WMF Martins Fontes, 2010.

. O Império do Direito. 3. ed. Tradutor: Jefferson Luiz Camargo. São Paulo: Editora WMF Martins Fontes, 2014.

GADAMER, Hans-Georg. Verdade e Método I: traços fundamentais de uma hermenêutica filosófica. 9. ed. Tradução de Flávio Paulo Meurer. Rio de Janeiro: Vozes, 2008.

LOPES FILHO, Juraci Mourão. Os precedentes judiciais no constitucionalismo brasileiro contemporâneo. Salvador: Juspodivm, 2014. 
. Precedente e norma: usam-se precedentes judiciais como se aplicam normas legislativas? Revista Opinião Jurídica (Fortaleza), v. 14, p. 231-252, 2013.

MÜLLER, Friedrich. O novo paradigma do direito: introdução à teoria e metódica estruturantes. 3. ed. rev. atual. e ampl. São Paulo: Editora Revista dos Tribunais, 2013.

. Teoria Estruturante do Direito I. 3. ed. rev. e atual. São Paulo: Editora Revista dos Tribunais, 2011.

OLIVEIRA, Manfredo Araújo de. A Reviravolta Linguístico-Pragmática na Filosofia Contemporânea. São Paulo: Loyola, 2006.

SCHMITZ, Leonard Ziesemer. Fundamentação das decisões judiciais: a crise na construção de respostas no processo civil. São Paulo: Editora Revista dos Tribunais, 2015.

STRECK, Lenio Luiz. O efeito vinculante das súmulas e o mito da efetividade: uma crítica hermenêutica. In: BONAVIDES, Paulo; LIMA, Francisco Gérson Marques de; BEDÊ, Fayga Silveira. (Coord.). Constituição e Democracia - Estudos em homenagem ao Professor J. J. Gomes Canotilho. São Paulo: Malheiros, 2006, p. 395-434.

. Hermenêutica jurídica e(m) crise: uma exploração hermenêutica da construção do Direito. 11. ed. rev., atual. e ampl. Porto Alegre: Livraria do Advogado, 2014,

TOULMIN, Stephen. Os usos do argumento. Traduzido por Reginaldo Guarany. 2. ed. São Paulo: Martins Fontes, 2006. 